\title{
Investigation of the Effects of Basalt Fibers on the Flexural Strength of RC Beams without Stirrups
}

\author{
Uğur ÖZGEN ${ }^{1}$ and Güray ARSLAN ${ }^{2}$
}

\begin{abstract}
This research studied the influence of chopped basalt fibers (BFs) on the shear strength of reinforced concrete (RC) beams without stirrups. The beams including one reference and three basalt fiber reinforced concrete (BFRC) beams were tested under concentrated load at mid-span to determine the shear strength. The test parameters are volume fraction of basalt fibers $\left(\mathrm{V}_{\mathrm{f}}\right)$ and shear span-to-effective depth ratio $(\mathrm{a} / \mathrm{d})$ of beam. The deflection of the beam and the cracking pattern were monitored during the test at certain stages of the monotonic loading until failure. It is observed that the contribution of BFs to the strength at the ultimate state decreases as volume fractions of BFs increase from $0 \%$ to $1.5 \%$.
\end{abstract}

Keywords-Reinforced concrete, beam, chopped basalt fibers, shear strength, deflection.

\section{INTRODUCTION}

$I^{1}$ n spite of having high compressive strength, proper bonding characteristics and ease of handling, concrete still needs to be used with additional materials for low tensile strength. Technological developments and recent studies have given cause for using new techniques instead of traditional construction materials. Adding fibers into concrete is one of the most promising ways of ensuring high flexural strength without the use of stirrups. Steel and glass fibers have been commonly used in concrete, besides another fiber which has good characteristic properties, is basalt fiber (BF). Among various fiber materials, the use of basalt fiber reinforced concrete (BFRC) has many advantages such as relatively low cost, unlimited reserves, nonflammable, excellent sound and thermal insulator, easy and rapid application, etc [1].

While a substantial amount of researches has focused on the flexural behavior of steel fiber reinforced concrete (SFRC), glass fiber reinforced concrete (GFRC) and polypropylene fiber reinforced concrete (PFRC) beams [2-5], there exists a relatively limited amount of studies concerning the flexural behavior of BFRC beams. Branston et al. [6] tested RC beams to evaluate the potential use of chopped fibers in preventing early age cracking and observed increase in the first cracking strength. Kabay [7] tested the effects of basalt fiber addition in high strength and normal strength concrete with different

Uğur ÖZGEN ${ }^{1}$ is with the Institute of Natural and Applied Sciences, Yildiz Technical University, Istanbul, 34220 TURKEY

Guray $\mathrm{ARSLAN}^{2}$, was with Civil Engineering Department, Yildiz Technical University, Istanbul, 34220 TURKEY water-to-cement ratios in terms of physical and mechanical properties. An increase in flexural strength up to $13 \%$ is observed. Issa et al. [8] examined the shear strength and behavior of concrete beams reinforced with basalt fiberreinforced polymer bars with and without stirrups and observed significant improvements in the shear strength of RC beams with insufficient shear reinforcement strengthened with BFRP. High et al. [9] investigated the use of basalt fiber bars as flexural reinforcement for concrete members and the use of chopped basalt fibers as an additive to enhance the mechanical properties of concrete. Jiang et al. [10] studied the effects of the volume fraction and length of $\mathrm{BF}$ on the mechanical properties of fiber reinforced concrete and observed significant improvements in the tensile strength and flexural strength in their experiments.

This paper presents four beams without stirrups tested to investigate the influence of $\mathrm{BF}$ on the $\mathrm{RC}$ beam strength. The beams with a shear span to effective depth $(\mathrm{a} / \mathrm{d})$ ratio of 6.0 and fiber contents $\left(\mathrm{V}_{\mathrm{f}}\right)$ of $0 \%, 0.5 \%, 1.0 \%$ and $1.5 \%$ by volume were tested under a concentrated load at mid-span.

\section{EXPERIMENTAL PROGRAM - TEST SPECIMENS}

A combination of letters and numbers is used for specimen labels: "C" followed by the shear span-to-effective depth ratio to indicate all test specimens in this research and " $\mathrm{B}$ " followed by the volume fraction of BFs. For example, a beam having a shear span-to effective depth ratio of 6.0 with a volume fraction of fibers equal to $1.0 \%$ is labeled as C6.0B1.0. The specimen labeled as $\mathrm{C} 6.0 \mathrm{R}$ is the reference beam that does not contain any fibers.

TABLE I

PROPERTIES OF BEAMS

\begin{tabular}{lc}
\hline \hline \multicolumn{1}{c}{ Materials } & $\begin{array}{c}\text { Mix Proportions } \\
\left(\mathrm{kg} / \mathrm{m}^{3}\right)\end{array}$ \\
\hline 0-1 mm Natural Sand & 350 \\
0-3 mm Crushed Sand & 550 \\
5-12 mm Crushed Stone & 1000 \\
Cement CEM I 42·5R & 300 \\
Water & 165 \\
Superplasticiser & 3 \\
\hline \hline
\end{tabular}

The concrete mix proportions for all beams are given in Table 1. The properties of test specimens are given in Table 2, where $\rho$ is the tensile reinforcement ratio, $V_{f}$ is the volume 
fraction of fibers and $f_{c}$ is the concrete compressive strength.

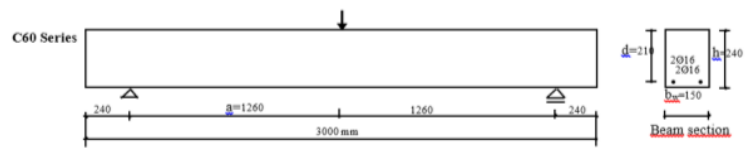

Fig. 1 Geometry and Reinforcement Arrangement of Beams

All beams have the same cross-section of $150 \mathrm{~mm}$ by 240 $\mathrm{mm}$ with an effective depth of $210 \mathrm{~mm}$ and are $3000 \mathrm{~mm}$ long. The shear span-to-effective depth ratios $(\mathrm{a} / \mathrm{d})$ of all beams are 6.0. Deformed bars with diameters of $16 \mathrm{~mm}$ were used as the tensile reinforcement. The geometrical properties and reinforcement arrangement of test specimens are shown in Figure 1.

TABLE II

PROPERTIES OF BEAMS

\begin{tabular}{llccccc}
\hline \hline Beams & $\begin{array}{c}\mathrm{f}_{\mathrm{c}} \\
(\mathrm{MPa})\end{array}$ & $\begin{array}{c}\mathrm{V}_{\mathrm{f}} \\
(\%)\end{array}$ & $\begin{array}{c}\rho \\
(\%)\end{array}$ & $\mathrm{a} / \mathrm{d}$ & $\begin{array}{c}\mathrm{a} \\
(\mathrm{mm})\end{array}$ & $\begin{array}{c}1 \\
(\mathrm{~mm})\end{array}$ \\
\hline C6.0R & 23.48 & -- & 1.28 & 6.0 & 1260 & 3000 \\
C6.0B0.5 & 19.905 & 0.5 & 1.28 & 6.0 & 1260 & 3000 \\
C6.0B1.0 & 14.72 & 1.0 & 1.28 & 6.0 & 1260 & 3000 \\
C6.0B1.5 & 7.38 & 1.5 & 1.28 & 6.0 & 1260 & 3000 \\
\hline \hline
\end{tabular}

The chopped BFs with a length and a diameter of $12 \mathrm{~mm}$ and $9-23 \mu \mathrm{m}$, respectively, were used throughout the study at varying contents. The density of BFs is $2.8 \mathrm{~g} / \mathrm{cm}^{3}$.

\section{TESTING AND INSTRUMENTATION}

A displacement-controlled loading machine (Fig. 2) was used to load the beams at mid-span with a static loading rate of $30 \mu \mathrm{m} / \mathrm{s}$. A computer-aided data acquisition system was used to determine the time intervals for recordings. The applied load and the deflections at various locations were recorded at those predetermined time intervals. The net deflections were recorded by using potentiometric displacement transducers. The beams were loaded until either failure or the load dropped below approximately $80 \%$ of its peak value.

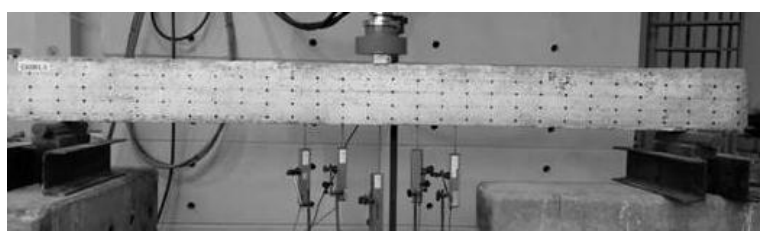

Fig. 2 Test setup

\section{RESULTS AND FINDINGS}

The crack patterns of tested beams are shown in Figure 3-6. At the early stages of loading, fine vertical cracks were observed around the mid-span of all beams as expected. As the load was increased, new flexural cracks appeared away from the mid-span area. Some of these cracks were gradually inclined towards the loading point with further increases in the applied loads and the applied load reached its maximum value with the formation of first diagonal crack. The loads carried by the beams decreased rapidly and the C6.0B1.0 and C6.0B1.5 beams failed in shear. While C6.0R and C6.0B0.5 beams exhibited flexural and flexure-shear failures, respectively.

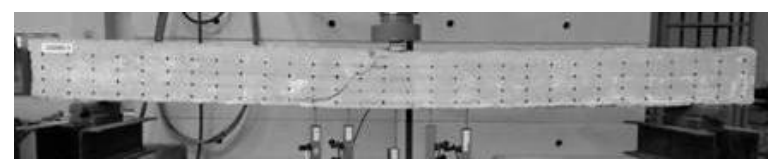

Fig. 3 Crack pattern of C6.0R

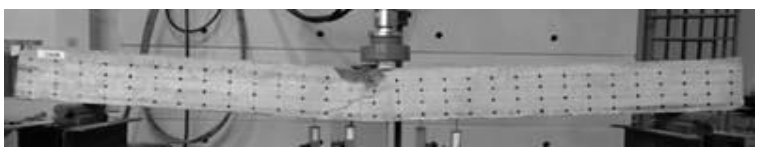

Fig. 4 Crack pattern of C6.0B0.5

Experimental results are summarized in Table 3, where $\mathrm{P}_{\mathrm{co}}$ and $\delta_{\text {co }}$ are the maximum load and the mid-span deflection at the maximum load, respectively, $\mathrm{P}_{\mathrm{u}}$ and $\delta_{\mathrm{u}}$ are the ultimate load and mid-span deflection, respectively, and the dissipated energy is the area under the load-deflection curve, which is plotted for each beam in Figure 7 and 8.

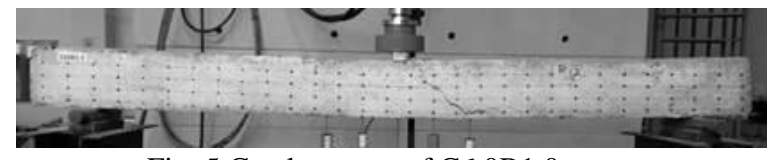

Fig. 5 Crack pattern of C6.0B1.0

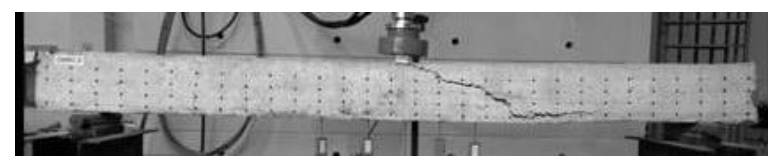

Fig. 6 Crack pattern of C6.0B1.5

The use of BFs in the amount of $0.5 \%$ and $1.0 \%$ by volume improved the maximum load of RC beams very slightly. Introducing BFs in the amount of $1.5 \%$ by volume resulted in a significant decrease in the load-carrying capacity. The deflection capacity of C6.0B1.0, the load-carrying capacity of which dropped immediately after reaching the peak value, was observed to be much less than those of others. It is observed in Figure 7 and Figure 8 that the initial stiffness of all beams are approximately the same except C6.0B1.5.

TABLE III

EXPERIMENTAL LOAD AND DEFLECTION VALUES OF BEAMS

\begin{tabular}{lcccccc}
\hline \hline Beams & $\begin{array}{c}\mathrm{P}_{\mathrm{co}} \\
(\mathrm{kN})\end{array}$ & $\begin{array}{c}\mathrm{P}_{\mathrm{u}} \\
(\mathrm{kN})\end{array}$ & $\begin{array}{c}\delta_{\mathrm{co}} \\
(\mathrm{mm})\end{array}$ & $\begin{array}{c}\delta_{\mathrm{u}} \\
(\mathrm{mm})\end{array}$ & $\begin{array}{c}\delta_{\mathrm{u}} / \\
\delta_{\mathrm{co}}\end{array}$ & $\begin{array}{c}\text { Dissipated } \\
\text { Energy } \\
(\mathrm{kNm})\end{array}$ \\
\hline C6.0R & 55.58 & 44.46 & 26.94 & 51.08 & 1.89 & 2.4102 \\
C6.0B0.5 & 57.54 & 46.03 & 15.70 & 26.22 & 1.67 & 1.0562 \\
C6.0B1.0 & 58.61 & 46.88 & 15.42 & 16.28 & 1.05 & 0.5798 \\
C6.0B1.5 & 34.75 & 27.80 & 14.58 & 22.92 & 1.57 & 0.6027 \\
\hline \hline
\end{tabular}




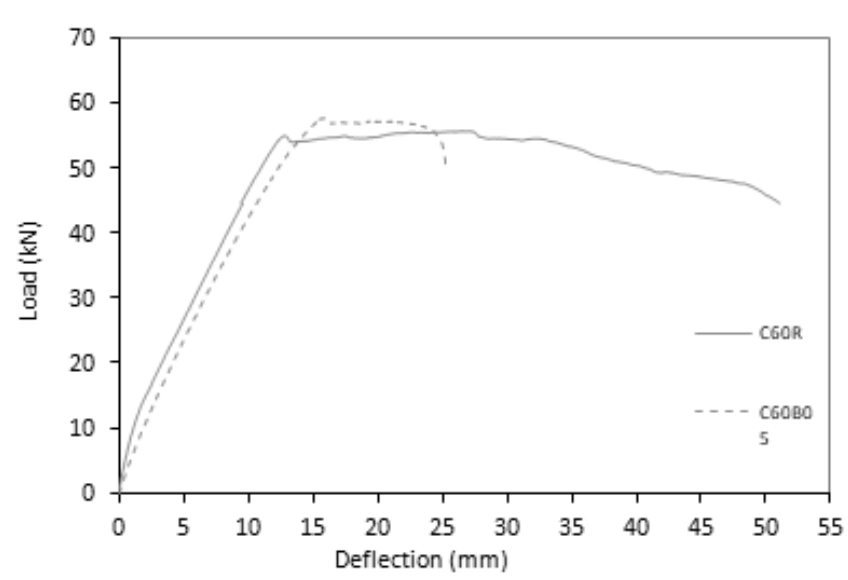

Fig. 7 Load-deflection curves

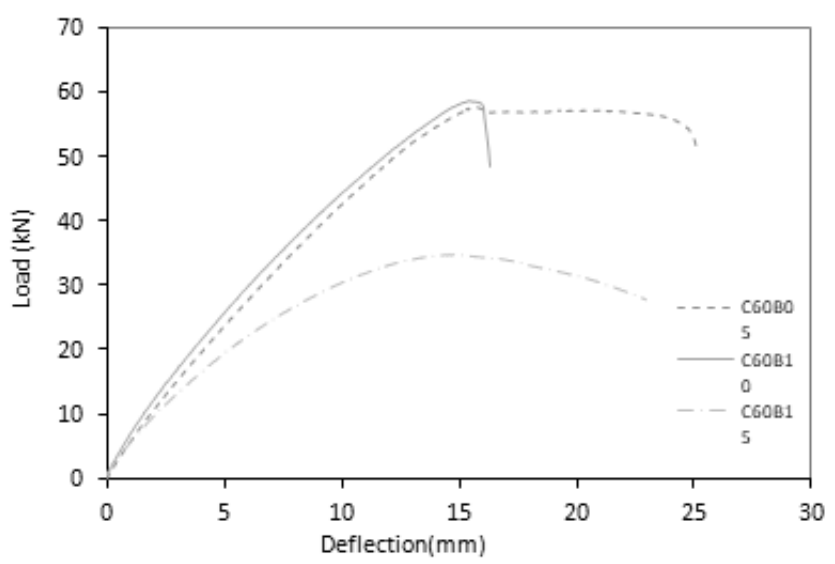

Fig. 8 Load-deflection curves of beams

\section{V.CONCLUSION}

The following conclusions are drawn based on the experiments of BFRC beams.

The beam having basalt fibers in the amount of $0.5 \%$ and $1.0 \%$ by volume reached a maximum load similar to the load reached by the reference beam, then the load decreased rapidly while a certain amount of deflection of the reference beam was observed beyond the maximum load without a significant loss in the load-carrying capacity. In case of the beam having basalt fibers in the amount of $1.0 \%$ by volume, the load decreased immediately after reaching the maximum value.

Introducing basalt fibers in the amount of $1.5 \%$ by volume resulted in a significant decrease in the load-carrying capacity. The load-carrying capacity was reduced by $45 \%$.

It is observed that the addition of basalt fibers was not able to improve the strength and ductility of RC beam. Contrarily, it resulted in a behavior poorer than the behavior of reference beam. This can be attributed to the inadequate bonding between aggregate and concrete due to the adhering of basalt fibers to aggregate while mixing the fibers with concrete.

\section{ACKNOWLEDGMENT}

This work was supported by Research Fund of Y1ldiz Technical University under Project No. FYL-2017-3034.

\section{REFERENCES}

[1] K. Singha. "A short review on basalt fiber," Int J Text, vol. 1, no. 4, pp. 19-28, 2012.

[2] T. Uygunoglu. "Investigation of microstructure and flexural behavior of steel-fiber reinforced concrete." Mater Struct, vol. 41, no. 8, pp. 1441-1449, 2008. https://doi.org/10.1617/s11527-007-9341-y

[3] A. Alzate, A. Arteaga, A. de Diego and R Perera. "Shear strengthening of reinforced concrete beams using fibre reinforced polymers (FRP)," Eur J Env Civ Eng, vol. 13, no. 9, pp. 1051-1060, 2009. https://doi.org/10.1080/19648189.2009.9693172

[4] H. Aoude, M. Belgidi, W. Cook and J. Mitchell, "Response of stell fiber-reinforced concrete beams with and without stirrups," ACI Struct $J$, vol. 103, no. 3, pp. 350-368, 2012.

[5] G. Arslan, R. S. O. Keskin and Ozturk, M., "Shear behaviour of polypropylene fibre-reinforced-concrete beams without stirrups," Proc Inst Civ Eng Struct Build, vol. 170, no. 3, pp. 190-198, 2017. https://doi.org/10.1680/jstbu.16.00202

[6] J. Branston, D. Sreekante, S. Y. Kenno and C. Taylor, "Mechanical Behaviour of basalt fibre reinforced concrete," Constr Budilg Mater, Vol. 124, no. 3, pp. 878-886, 2016.

https://doi.org/10.1016/j.conbuildmat.2016.08.009

[7] N. Kabay. "Abrasion resistance and fracture energy of concretes with basalt fiber," Constr Build Mater, vol. 50, pp. 95-101, 2014 https://doi.org/10.1016/j.conbuildmat.2013.09.040

[8] M. Issa, T. Ovitigala and M. Ibrahim. "Shear Behavior Basalt Fiber Reinforced Concrete Beams with and without Basalt FRP Stirrups." $J$ Compos Constr., 2016, vol. 20, no. 4. https://doi.org/10.1061/(ASCE)CC.1943-5614.0000638

[9] C. High, H. M. Seliem, A. El-Safty and S. H. Rizkalla, "Use of basalt fibers for concrete structures," Constr Build Mater, vol. 96, pp. 37-46, 2015. https://doi.org/10.1016/j.conbuildmat.2015.07.138

[10] C. Jiang, K. Fan, F. Wu and D. Chen. "Experimental study on the mechanical properties and microstructures of chopped basalt fiber reinforced concrete," Mater Des., vol. 58, no. 1, pp. 187-193, 2014. https://doi.org/10.1016/j.matdes.2014.01.056 